\title{
Microbiological study in a gneissic cave from Sri Lanka, with special focus on potential antimicrobial activities
}

\author{
Ethige Isuru P. Silva (D) ${ }^{1}$, Pathmakumara Jayasingha (1D ${ }^{3,4}$, Saman Senanayake ${ }^{4}$ \\ Anura Dandeniya ${ }^{4}$, and Dona Helani Munasinghe (iD ${ }^{1,2^{*}}$ \\ ${ }^{1}$ Department of Botany, Faculty of Applied Sciences, University of Sri Jayewardenepura, Gangodawila, Nugegoda, Sri Lanka \\ ${ }^{2}$ Centre for Plant Materials and Herbal Products Research, University of Sri Jayewardenepura, Gangodawila, Nugegoda, Sri Lanka \\ ${ }^{3}$ Department of Geography, University of Colombo, Colombo 03, Sri Lanka \\ ${ }^{4}$ Lanka Institute of Cave Science (LICAS), 1/66 Mayura Mawatha, Pepiliyana, Sri Lanka
}

\begin{abstract}
The emergence of antibiotic resistance is a global health crisis, thus the search for novel antimicrobial compounds has become a continuous necessity. Underexplored and extreme environments, such as cave ecosystems, have been identified as a promising potential source for the discovery of novel microorganisms with novel antimicrobial compounds (AMC). This study presents the first cave microbiological investigation in Sri Lanka, with a special preference for bioprospecting of novel AMC. The cave sediment characterization demonstrated the presence of close to strong acidic conditions $(\mathrm{pH} 3.1-3.3)$ and thus indicates the possibility of isolating acidophilic microorganisms. Eight cave wall/ceiling fungal strains were isolated from Sthreepura Cave - Kuruwita and identified using both morphological and ribosomal Internal Transcribed Spacer (ITS) region sequence analysis. Interestingly, four fungal isolates (Penicillium panissanguineum, P. cremeogriseum, Aspergillus bertholletius and Trichoderma yunnanense) were found to be the first records in Sri Lanka. Of these eight isolates, three showed antimicrobial activity (AMAs) against at least one of the five tested human pathogens in preliminary screening, while A. fumigatus (SKW 404) strain showed the highest AMA against Staphylococcus aureus (ATCC 11778) assessed by agar culture plug method on Muller Hinton Agar (MHA). Crude Ethyl Acetate (EtOAc) fraction of both mycelial and Potato Dextrose Broth (PDB) extracts of $A$. fumigatus demonstrated similar bioactive metabolic profiles with four corresponding chemical fractions $\left[\mathrm{R}_{f}=0.47,0.56,0.65,0.82\right.$; EtOAc: Hexane (4:1, v/v)] in TLC: agar overlay bioassay. The present study indicates that there is potential for discovering novel Sri Lankan deep cave microorganisms and bioprospecting of their novel bioactive compounds. Hence, further island-wide in-depth cave microbiological investigations are required for a better understanding of the Sri Lankan cave microbiology.
\end{abstract}

Keywords: Cave microorganisms, Sthreepura Cave - Kuruwita, Bioprospecting, Antimicrobial activities, Aspergillus fumigatus

Received 8 August 2020; Revised 1 March 2021; Accepted 2 March 2021

Citation: Silva E.I.P., Jayasingha P., Senanayake S., Dandeniya A. and Munasinghe D.H., 2021. Microbiological study in a gneissic cave from Sri Lanka, with special focus on potential antimicrobial activities. International Journal of Speleology, 50 (1), 41-51. Tampa, FL (USA) ISSN 0392-6672 https://doi.org/10.5038/1827-806X.50.1.2343

\section{INTRODUCTION}

Sri Lanka is a tropical island in the Indian Ocean with very high biodiversity and a diverse array of geological characteristics compared to its size. This includes a high density of caves with an astounding diversity of morphology and its genesis. Until recently, most of the studies conducted on caves were based on archaeological and faunal investigations and a few were based on geological aspects (Jayasingha et al., 2010; Weliange et al., 2010; Osborne et al., 2013; Sumanarathna et al., 2016; Jayasingha et al., 2018). Surprisingly, the presence of some visible microbial colonies and microbiological formations within these cave ecosystems are reported in a few publications as well (Weliange et al., 2010; Osborne et al., 2013). However, there is no published evidence on previous cave microbiological studies conducted in Sri Lanka, focusing on isolation, identification and bioprospecting of these unique cave microorganisms.

Antibiotics have become an essential utility in medicine leading to an over-usage. The overuse and misuse of antibiotics eventually have resulted in antibiotic resistance in many human pathogenic 
bacteria against a diverse array of clinically important drugs leading to a global health crisis (Clatworthy et al., 2007; Bennett, 2015). Although several other alternatives have been suggested for antibiotics, antibiotics are still unable to be replaced, given their importance in critical surgical procedures such as organ and prosthetic transplants involved in immunosuppression conditions (Davies \& Davies, 2010). Hence, novel antibiotics must be continuously discovered as it has become a global necessity (Spizek \& Havlicek, 2015).

Microorganisms can be considered as the best source for the discovery of natural antibiotics (Bérdy, 2015; Patridge et al., 2016). During the last few decades, microbiological investigation of both underexplored or unexplored extreme environments, such as deep oceanic environments, hot springs, deserts, polar areas and cave ecosystems has become the focal point of the scientific community (Spizek \& Havlicek, 2015), because these novel environments may reveal novel microorganisms with the capability of novel antibiotic production.

Caves are unique, underexplored, and extreme habitats isolated from the surrounding environment for thousands to millions of years which might contain novel microbial strains (Cheeptham, 2013; Gabriel \& Northup, 2013). Notably, most of the novel microorganisms discovered (using both culture and/ or molecular methods) in cave ecosystems were 'rare actinomycetes', which have a higher likelihood of isolating novel antibiotics (Cheeptham \& SáizJiménez, 2015). Moreover, oligotrophic conditions in many caves have been shown to result in higher antimicrobial activities due to increased competition between different microbial taxa for limited resources (Montano \& Henderson, 2013). For example, Hamedi et al. (2019) have reported around 25\% of cave isolates to have at least one type of antimicrobial activity. However, the number of investigations on these microorganisms in search of novel antibiotics is relatively low, limiting to a few antimicrobial compounds. Among these, Cervimycin A-D complex was isolated from an Italian cave-dwelling Streptomyces species which is considered to be one of the most promising discoveries, due to its antimicrobial activities against Methicillin-resistant Staphylococcus aureus (MRSA), vancomycin-resistant Enterococcus species, Gram-negative bacteria and fungi (Herold et al., 2005). However, isolation of cave microorganisms in search of antimicrobial compounds is a challenging process (Cheeptham, 2013). Caving requires preplanning and preparedness and extreme endurance along with a proper team equipped with special safety equipment, since the sampling processes are carried out in dark and risky environment (Moser et al., 2003; Weliange et al., 2010; Cheeptham, 2013). Moreover, the selection of proper media and incubation conditions are critical factors, since it has been estimated that only $1 \%$ of cave microorganisms are cultivable (Amann et al, 1995; Cheeptham, 2013).

The current research was conducted with the primary objective of initiating microbiological studies on Sri Lankan Caves. For this, among all the known caves in Sri Lanka, Sthreepura Cave - Kuruwita was chosen, since it is a well-studied cave with adequate speleological background information, making it the most promising candidate for this initial cave microbiological study (Weliange et al., 2010; Osborne et al., 2013). In this study, the main objectives were to isolate and identify some cave-dwelling microorganisms in Sthreepura Cave - Kuruwita, Sri Lanka and to screen and evaluate their potential antimicrobial activities.

\section{MATERIALS AND METHODS}

\section{Cave description}

Sthreepura Cave - Kuruwita (06 49' 54.6" N and $\left.08^{\circ} 22^{\prime} 27.8^{\prime \prime} \mathrm{E}\right)$ is an underground cave located in Rathnapura district, Sri Lanka. The entrance is situated at an elevation of $322 \mathrm{~m}$ mean sea level and about $75 \mathrm{~m}$ east of a famous archaeological site known as Batathota Lena (Cave) (Weliange et al., 2010; Osborne et al., 2013). However, it experiences a very low visitor pressure as it is situated in a cliff base with an unmarked trail to the cave surrounding a highly dense tropical wet zone rainforest which makes it very difficult to reach.

The length of the Sthreepura cave - Kuruwita is approximately $80 \mathrm{~m}$ to its northern end and extends perpendicular to the cliff line. It consists of eight main compartments: 'Welcome Chamber' (WC), 'Connecting Passage' (CP), 'Guano chamber' (GC), 'Passage of bats' (PB), a connecting rift and three small tubes as described by Weliange et al. (2010; Fig. 1).

The Sthreepura Cave - Kuruwita is located in a Proterozoic metamorphic silicate rock terrain of the highland complex. Based on the morphology and its genesis, Sthreepura Cave - Kuruwita has categorized as one of the two block breakdown caves in Sri Lanka (Jayasingha et al., 2010; Osborne et al., 2013). Most of the cave (including the wall, ceiling and fallen blocks) is formed in gneiss while dolomite is exposed in only a limited area at the northwest corner of the GC. The cave is mainly inhabited by microbats and few other species of arthropods (Weliange et al., 2010).

\section{Sample collection}

Cave sediments and wall/ceiling samples were collected from Sthreepura Cave - Kuruwita on $28^{\text {th }}$ July 2019 (between 11:30 and 14:30) under a special sample collection permit (D.Arch/HO/Pro/Permit III) issued by the Department of Archeology, Sri Lanka. Samples were collected from three sediment sampling locations and four cave wall/ceiling microbial sampling locations. Considering the limitation of resources and difficulties of sampling only the first two compartments (WC, CP) were sampled. Onsite culturing was performed with the use of selective isolation media, Starch Casein Nitrate Agar (SCNA; composition: Bacto Agar/ Agar: 15.0 g, Sodium propionate; 4.0 g, Casein; $2.0 \mathrm{~g}, \mathrm{~K}_{2} \mathrm{HPO}_{4}$ : $0.5 \mathrm{~g}$, L-Asparagine: $0.1 \mathrm{~g}, \mathrm{MgSO}_{4} \cdot 7 \mathrm{H}_{2} \mathrm{O}$ : $0.1 \mathrm{~g}, \mathrm{FeSO}_{4} \cdot 7 \mathrm{H}_{2} \mathrm{O}: 0.001 \mathrm{~g}$, Glycerol: $5.0 \mathrm{~mL}, \mathrm{pH}$ : $7.1 \pm 0.1$ ) and Actinomycetes Isolation Agar (AIA; composition: Bacto Agar: $18.0 \mathrm{~g}$, Soluble starch: 10.0 g, $\mathrm{K}_{2} \mathrm{HPO}_{4}: 2.0 \mathrm{~g}, \mathrm{KNO}_{3}: 2.0 \mathrm{~g}, \mathrm{NaCl}: 2.0 \mathrm{~g}$, Casein: 0.3 


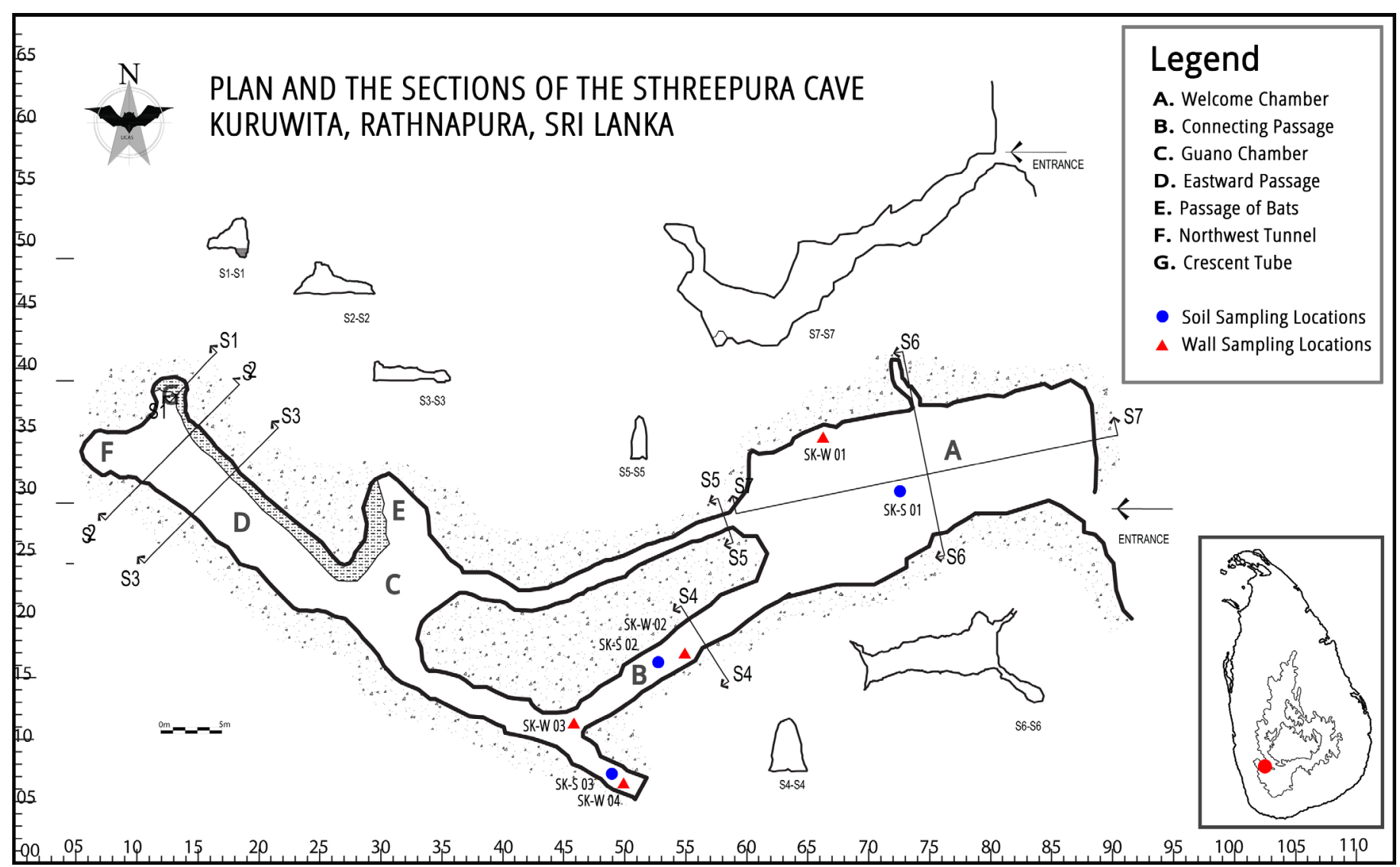

Fig 1. Plan and the sections of the Sthreepura Cave - Kuruwita annotated with cave sediment and cave wall/ceiling sampling locations. Samples were collected only within the zone one (Welcome Chamber [A] and Connecting Passage [B]). Map modified after LICAS (Dandeniya et al., 2009).

g, $\mathrm{CaCO}_{3}: 0.02 \mathrm{~g}, \mathrm{MgSO}_{4} \cdot 7 \mathrm{H}_{2} \mathrm{O}: 0.05 \mathrm{~g}, \mathrm{FeSO}_{4} \cdot 7 \mathrm{H}_{2} \mathrm{O}$ : $0.01 \mathrm{~g}, \mathrm{pH} 8.1 \pm 0.2)$ supplemented with Nalidixic acid $(20 \mu \mathrm{g} / \mathrm{mL})$. Samples of the visible microbial colonies on the cave walls and cave ceilings were collected and inoculated using sterile cotton swabs (Yücel \& Yamaç, 2010; Montano \& Henderson, 2013). All cave sediment samples were collected aseptically as the methods recommended by Moser et al. (2003) and Fisher et al. (2015). Accordingly, the cave sediment samples were collected from the depth of $2.0-5.0 \mathrm{~cm}$ from the upper sediment layer and they were placed in sterile $50 \mathrm{~mL}$ Falcon tubes and then further stored in small zip-top bags. Both cave sediment samples and onsite culture plates were stored in a small shipping cooler and transported to the laboratory within $15 \mathrm{~h}$. The samples were processed immediately or stored at $4^{\circ} \mathrm{C}$ until further use. All the onsite cultured plates were incubated for seven days at $25^{\circ} \mathrm{C}$ under dark conditions to mimic its natural environmental parameters.

\section{Measurement of cave sediment $\mathrm{pH}$ and moisture content}

Sediment samples were air-dried at room temperature for 7 days and then ground and sieved through a $2 \mathrm{~mm}$ mesh sieve. The resulting sediment portions were saturated with distilled water and the paste was allowed to equilibrate for 1 hour. The readings were taken with the use of a glass electrode pH meter (Reed \& Cummings, 1945).

Cave sediment moisture content (CSMC) was measured as described by Williams and Davies (1970). Fresh cave sediment samples of known weights were oven-dried at $105^{\circ} \mathrm{C}$ until constant weight. The resulting weight losses were calculated and the CSMC was expressed as an average of three replicates.

\section{Selective isolation and enumeration of cave sediment bacteria}

Dilution plate technique was performed for the isolation of actinobacteria from fresh cave sediment samples (Cheeptham et al., 2013; Belyagoubi et al., 2018). Within $24 \mathrm{~h}$ of the cave sampling process, one gram of fresh sediment sample from each sample was suspended in $9.0 \mathrm{~mL}$ of sterile $0.9 \% \mathrm{NaCl}$ solution $(\mathrm{w} / \mathrm{v})$, followed by successive serial dilutions up to $10^{-4}$. An aliquot of $100 \mu \mathrm{L}$ of each suspension was inoculated onto SCNA supplemented with Nalidixic acid $(20 \mu \mathrm{g} / \mathrm{mL})$ and Nystatin $(25 \mu \mathrm{g} / \mathrm{mL})$ to inhibit the growth of gram-negative bacteria and fungi, respectively. All the plates were incubated for six weeks at $25^{\circ} \mathrm{C}$ in dark conditions. The presence of actinobacterial colonies was monitored on a weekly basis during the incubation period.

\section{Obtaining the pure cultures of cave wall/ceiling dwelling microorganisms}

Both bacterial and fungal isolates which were obtained from the onsite cave wall and ceiling samples were initially streaked to purify and subcultured on SCNA and Potato Dextrose Agar (PDA; HiMedia Laboratories, Mumbai, India) respectively. Further purification of fungal isolates was achieved with a modified hyphal tip transfer method as described by Paul et al. (2014). Bacterial and fungal pure culture stocks were maintained in SCNA and PDA slants at $4^{\circ} \mathrm{C}$ respectively. 
Identification of cave wall/ceiling fungal isolates

Eight fungal isolates were selected for further identification based on their different colony morphological characteristics and respective sampling locations. For the identification, 7-10 day old pure cultures were obtained using a single spore isolation method as described in Choi et al. (1999). Initially,-morphological characteristics of fungi were examined to identify up to the genus level under a light microscope (B-350 OPTIKA) using the slide culture method (Cappuccino et al., 2017). Further identification of the fungi was done with the use of molecular methods. The extraction of fungal gDNA was carried out according to the protocol described by Arnold \& Lutzoni (2007). The ITS-1 (5' TCC GTA GGT GAA CCT GCG G 3') forward and ITS-4(5' TCC TCC GCT TAT TGA TAT GC 3') reverse primer pair was used for the Polymerase Chain Reaction (PCR) amplification of ITS fungal barcode region (White et al., 1990). The target sequences were amplified on a BIORAD T100 ${ }^{\mathrm{TM}}$ Thermal Cycler with initial denaturation of 3 minutes at $95^{\circ} \mathrm{C}$, followed by 30 cycles of $30 \mathrm{~s}$ at $94^{\circ} \mathrm{C}, 30 \mathrm{~s}$ at $52^{\circ} \mathrm{C}, 1 \mathrm{~min}$ at $72^{\circ} \mathrm{C}$ and with the final extension of 10 minutes at $72^{\circ} \mathrm{C}$, in a $25 \mu \mathrm{L}$ reaction mixture which was prepared by adding $1 \mu \mathrm{L}$ of extracted gDNA into $24 \mu \mathrm{L}$ of GoTaq Colorless Master Mix as recommended by the manufacturer. PCR products were verified by gel electrophoresis and were commercially sequenced by Macrogen, Inc. (Korea) in both directions. Sequence contigs were assembled using BioEdit v7.2.5 (for windows) and were identified using standard nucleotide BLAST [National Center for Biotechnology Information (NCBI)].

\section{Agar cylinder method for the preliminary screening of cave wall/ceiling fungal isolates}

The potential antimicrobial activities of each fungal isolate were assessed by the presence of inhibition zones against five human pathogenic microorganisms; Staphylococcus aureus (ATCC 11778), Escherichia coli (ATCC 25922), Pseudomonas aeruginosa (ATCC 25853), Candida albicans (ATCC 10231) and Candida parapsilosis (ATCC 22019) using agar culture plug method as described by Belyagoubi et al. (2018) and according to the guidelines given by Clinical \& Laboratory Standards Institute (CLSI, 2015). All microbial cultures were kindly provided by the Department of Microbiology, Faculty of Medical Sciences, University of Sri Jayewardenepura, Sri Lanka (USJ).

In brief, bacterial and yeast suspensions with the similar optical density of McFarland 0.5 were prepared in sterile saline water using bacteria grown for $24 \mathrm{~h}$ (S. aureus, E. coli, and P. aeruginosa) and yeast cultures grown for $48 \mathrm{~h}$ (C. albicans and $C$. parapsilosis) at $37^{\circ} \mathrm{C}$. Agar culture plugs $(6 \mathrm{~mm}$ in diameter) from the isolated cave wall/ceiling fungal cultures grown on antibiotic-free PDA and SCNA for 10 days at $25^{\circ} \mathrm{C}$ were placed on pathogen seeded agar plates. Chloramphenicol (30 $\mathrm{\mu g} /$ disk) and Gentamicin (10 ug/disk) were used as positive controls against Gram-positive and Gram-negative bacteria respectively. Ketoconazole (10 $\mu \mathrm{g} /$ disk) was used as the positive control against both Candida species. Prior to incubation at $37^{\circ} \mathrm{C}$, the plates were placed in a refrigerator $\left(4^{\circ} \mathrm{C}\right)$ for 1 hour to allow the diffusion of any antimicrobial compounds in the agar cylinder. The zone of inhibition (ZOI) of each positive culture was recorded after incubating $24 \mathrm{~h}$ and $48 \mathrm{~h}$ for bacteria and Candida species, respectively.

\section{Submerge fermentation and extraction of antimicrobial compounds}

Based on primary screening results, fungal isolate SKW 404 was selected for the production of desired antimicrobial compounds. The isolate was grown on antibiotic-free PDA plates at $25^{\circ} \mathrm{C}$ for 10 days. Agar disks of $0.6 \mathrm{~mm}^{2}$ from culture plates of SKW 404 were inoculated into Erlenmeyer flasks containing $150 \mathrm{~mL}$ of sterile Potato Dextrose Broth (PDB) and kept on a rotary shaker at $150 \mathrm{rpm}$ for 15 days under room temperature (Cho et al., 2002; Trisuwan et al., 2009).

Following the incubation time, the PDB culture broths were filtered using No. 1 Whatman filter papers and the mycelia were separated. The resulting culture filtrate fractions $(50 \mathrm{~mL})$ were extracted three times with Ethyl Acetate (EtOAc, 1:1 v/v). All EtOAc fractions were pooled and evaporated to dryness under reduced pressure (Büchi rotary evaporator Model R-124) at $38^{\circ} \mathrm{C}$.

The separated mycelia were air-dried at $35^{\circ} \mathrm{C}$ for three days in an oven drier until they result in constant weight. Resulted mycelia were immersed in EtOAc $(1: 1 \mathrm{w} / \mathrm{v})$ for 20 minutes and then subjected to ultrasonication with $45 \mathrm{kHz}$ for 15 minutes at $37^{\circ} \mathrm{C}$ using an ultrasonicate bath (GT SONIC L-3). During the sonication process, the mixtures were placed in an ice bath for a five-minute interval to prevent any thermal damage. The homogenized mixtures were gently shaken on a rotary shaker at $150 \mathrm{rpm}$ for 30 minutes in room temperature and then centrifuged at $6000 \mathrm{rpm}$ for 15 minutes (Wang et al., 2013). The obtained EtOAc filtrates were then evaporated to dryness under reduced pressure.

The obtained dark brown gummy-like crude was redissolved in EtOAc to prepare a crude stock solution $(20 \mu \mathrm{g} / \mathrm{mL})$ and was stored at $4^{\circ} \mathrm{C}$ for further use.

\section{Kirby-Bauer (KB) disk diffusion assay}

Both PDB culture broth (extracellular) and mycelial (intracellular) EtOAc crude extracts isolated from SKW404 were tested against S. aureus using standard $\mathrm{KB}$ disk diffusion assay as described in Hudzicki (2009) with necessary modifications. Sterile paper disks (6 mm diameter) were impregnated with $20 \mu \mathrm{L}$ of the SKW 404 crude extracts and allowed to dry. They were placed on the surface of MHA (HiMedia Laboratories, Mumbai, India) plates seeded with $\mathrm{S}$. aureus and the plates were incubated at $37^{\circ} \mathrm{C}$ for $24 \mathrm{~h}$. Chloramphenicol disks (30 $\mu \mathrm{g} /$ disk) were used as the positive control while the negative control was EtOAc without any extracts. Antibacterial activity was evaluated by measuring the diameter of $\mathrm{ZOI}$ to the nearest millimetre. The results were expressed as the mean of three values with Standard Deviation (SD). 


\section{Thermo-stability test}

EtOAc crude fractions (both intracellular and extracellular) were divided into three portions (100 $\mu \mathrm{L}$ per Eppendorf tube) and were exposed separately to different temperatures $\left(35,55\right.$, and $\left.75^{\circ} \mathrm{C}\right)$ for 15 minutes in a hot water bath (Barakat \& Gohar, 2012). The thermo-stability was determined by KB disk diffusion assay as mentioned above against $S$. aureus.

\section{Thin Layer Chromatography (TLC): Bioautography}

TLC was performed following the guidelines given by Gibbons (2012). TLC plates (precoated Kieselgel 60 F254) with the size of $2 \mathrm{~cm} \mathrm{x} 6 \mathrm{~cm}$ were spotted with $10 \mu \mathrm{L}$ of EtOAc crude extracts of SKW 404 and developed under pre-saturated conditions with the solvent system as EtOAc: Hexane, 4/1 (v/v). Developed chromatograms were visualized under UV illumination at 254 and $365 \mathrm{~nm}$ (A. KRÜSS Optronic $\mathrm{GmbH}, \mathrm{UV}-$ and analysis lamp UV240) and Iodine vapour.

Agar overlay bioassay was performed on a developed TLC chromatogram as it provides well-defined inhibition zones and is less sensitive to contamination (Marston, 2011; Balouiri et al., 2016). Obtained TLC chromatograms were air-dried for 1 hour and then surface-sterilized for 5 minutes under UV (254 nm). For the preparation of a thin layer of agar on the TLC chromatograms, $50 \mathrm{~mL}$ of diluted $(0.66 \%)$ MHA was prepared and maintained in a water bath at $40^{\circ} \mathrm{C}$. Subsequently, $3 \mathrm{~mL}$ of S. aureus bacterial suspension (prepared to $0.5 \mathrm{McF}$ arland turbidity standard) was inoculated into the molten 0.66 MHA. The TLC plate was carefully overlaid with $\mathrm{S}$. aureus inoculated molten 0.66 MHA and was allowed to solidify at room temperature in a humid chamber, under aseptic conditions. The resulting TLC plates were kept at $4^{\circ} \mathrm{C}$ for 30 minutes to allow the best diffusion of antimicrobial compounds into agar medium and then incubated at $37^{\circ} \mathrm{C}$ for $24 \mathrm{~h}$. Following the incubation time, the TLC plates were flooded with a solution of Thiazolyl Blue Tetrazolium Blue (MTT) (Sigma), $2 \mathrm{mg} \mathrm{mL}^{-1}$ (in sterile distilled water) and were incubated for 1 hour at $37^{\circ} \mathrm{C}$ for better visualization of the microbial inhibition zones. Biologically active metabolites were identified and their corresponding $\mathrm{R}_{\mathrm{f}}$ values were calculated.

\section{RESULTS AND DISCUSSION}

\section{Cave sediment characterization}

Cave sediment characters such as $\mathrm{pH}$ and other nutrient conditions are critical to the success of isolating microorganisms from extreme environments. However, the available data on the Sri Lankan cave sediments is limited to a few geological aspects. Hence cave sediment characterization was performed to identify a few essential characteristics of Sthreepura Cave sediments for further microbiological investigations.
The colour of the sediment samples varied from dark brown to light brown. The sediments in the WC were completely made with humus derived from bat guano with no or very less small mica fragments while a relatively higher amount of mica fragments was observed in the other two samples. These observations are further confirmed by early reports of the cave by Osborne et al. (2013). Furthermore, CSMC highly varies depending on the sediment type and sampling locations, while sediment samples obtained from WC had the highest CSMC. The average $\mathrm{pH}$ values of the sediment samples were in a range of $\mathrm{pH} 3.13$ and $\mathrm{pH}$ 3.36 (Table 1), and the overall cave sediments had near strong acidic conditions.

Acidic cave sediments were also reported in other Asian caves including those in Israel, Malaysia and Thailand (Shahack-Gross et al., 2004; Niyomvong et al., 2012; Wurster et al., 2015). It has been found that caves inhabited with insectivorous bats consist of higher acidic sediments than other caves inhabited with fruit bats. Furthermore, the acidity of sediments seems to increase with depth (Shahack-Gross et al., 2004; Wurster et al., 2015).

According to Wurster et al. (2015), the presence of higher acidic conditions can be attributed to the bacterial processing of bat guano and urea within the cave ecosystem which causes the release of $\mathrm{CO}_{2}$, $\mathrm{NH}_{3}$, sulfuric acid and formic acid as byproducts while reducing $\mathrm{pH}$ along with organic carbon and nitrogen levels (thus, low in nutrients levels) in the lower sediments (Shahack-Gross et al., 2004; Wurster et al., 2015).

\section{Isolation of cave wall-dwelling microorganisms}

Based on colony morphology, six bacterial isolates and twelve fungal isolates from each sampling location were obtained from onsite (wall/ceiling swab) culture plates (Table 2). The highest number of different isolates (eight) were obtained from the culture plate swabbed with whitish microbial wall colony (sample ID: SK-W 04) present at the south-east tube of the CP (Fig. 2).

\section{Isolation and enumeration of cave sediment microorganisms}

A total of twelve actinobacterial isolates were obtained from non-treated fresh sediment samples. The highest number (six) of isolates were obtained from the sediment samples collected from South East tube of CP. Enumeration of cave sediment microorganisms failed since none of the sediment samples had the minimum required colonies.

According to Cheeptham (2013), adverse conditions such as low $\mathrm{pH}$ levels, limited nutrients and other stress conditions might lead the cultivable microorganisms to shift into their non-cultivable state although they are still viable. As such, the sediments

Table 1. Cave sediment sampling sites in the cave and their characteristics.

\begin{tabular}{|l|c|c|c|c|c|}
\hline \multicolumn{1}{|c|}{ Sampling Site } & Sample ID & Material description & Temperature $\left({ }^{\circ} \mathbf{C}\right)$ & $\mathbf{p H}(\mathbf{n}=\mathbf{3})$ & $\mathbf{C S M C} \%$ (n = 3) \\
\hline WC & SK-S 01 & Humus & 25 & $3.2 \pm 0.06$ & $66.10 \pm 1.05$ \\
\hline CP & SK-S 02 & Silt & 25 & $3.1 \pm 0.00$ & $21.46 \pm 0.91$ \\
\hline South-East tube of CP & SK-S 03 & Organic Silt & 24 & $3.3 \pm 0.06$ & $19.38 \pm 0.39$ \\
\hline
\end{tabular}


Table 2. Number of cave wall/ceiling isolates per each sampling location.

\begin{tabular}{|l|c|c|c|c|}
\hline \multicolumn{1}{|c|}{ Sample Site } & Sample ID & $\begin{array}{c}\text { Number of initial } \\
\text { Bacterial Isolates }\end{array}$ & $\begin{array}{c}\text { Number of initial } \\
\text { fungal Isolates }\end{array}$ & Total initial isolates \\
\hline WC & SK-W 01 & 1 & 3 & 4 \\
\hline CP & SK-W 02 & 4 & 1 & 5 \\
\hline CP & SK-W 03 & 0 & 1 & 1 \\
\hline South East tube of CP & SK-W 04 & 1 & 7 & 8 \\
\hline Grand total & & 6 & 12 & 18 \\
\hline
\end{tabular}
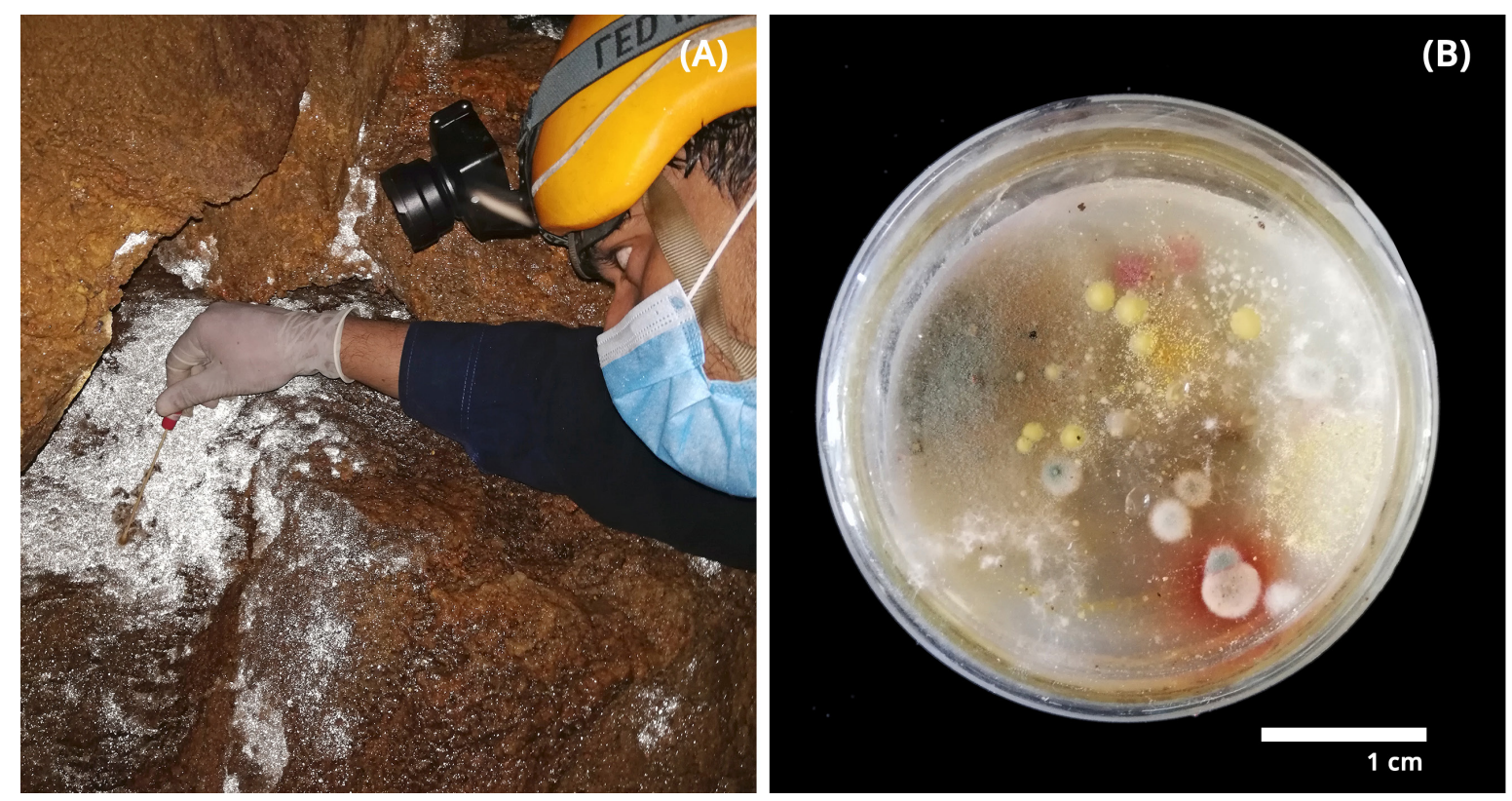

Fig 2. Isolation of cave wall microorganisms (A) Wall swab sampling of the whitish microbial colonies (sample ID SK-W 04) and (B) their corresponding isolates on SCNA after seven days of incubation period.

from the Sthreepura Cave - Kuruwita, which are found to contain lower $\mathrm{pH}$ levels, resulted in a reduced success rate of the isolation process, although the $\mathrm{pH}$ of the media was adjusted accordingly. Moreover, the exact nutrient composition of the bat guano derived sediments may not be provided by the given isolation media (SCNA and AIA), especially the isolation of rare cave sediment actinobacteria. The inability to culture some microorganisms can also be due to the low prevalence and/or slow growth, resistance to being cultured as monoculture isolates and dormancy or temporary state of low metabolic activity (Vartoukian et al., 2010).
Even though there were twelve cave sediment derived actinobacterial isolates, considering the unexpected extremely slow growth, limitation of the allocated timeline, funding and facilities, further investigations have not been performed using the actinomycetes isolates.

\section{Identification of cave wall/ceiling fungal isolates}

All the fungal isolates' microscopic characteristics were observed, and they were identified up to the genus level. Each isolate up to species level were later confirmed by the molecular data, as shown in Table 3.

Table 3. BLAST results of the cave wall/ceiling fungal isolates amplified with ITS sequences.

\begin{tabular}{|l|c|c|c|c|c|c|}
\hline \multicolumn{1}{|c|}{ Isolate } & $\begin{array}{c}\text { GeneBank } \\
\text { accession number }\end{array}$ & $\begin{array}{c}\text { Query } \\
\text { cover }\end{array}$ & E value & $\begin{array}{c}\text { Percentage } \\
\text { Identity }\end{array}$ & $\begin{array}{c}\text { GenBank accession number } \\
\text { of closest BLAST hit }\end{array}$ & $\begin{array}{c}\text { Identity of the reference } \\
\text { Isolate (type) }\end{array}$ \\
\hline SKW 104 & MW261807 & $100 \%$ & 0 & $98.56 \%$ & NR_158825.1 & $\begin{array}{c}\text { Penicillium panissanguineum } \\
\text { CBS 140989 }\end{array}$ \\
\hline SKW 201 & MW261808 & $99 \%$ & 0 & $98.79 \%$ & NR_138290.1 & $\begin{array}{c}\text { Penicillium simplicissimum } \\
\text { CBS 372.48 }\end{array}$ \\
\hline SKW 301 & MW261809 & $100 \%$ & 0 & $100 \%$ & NR_121481.1 & $\begin{array}{c}\text { Aspergillus fumigatus ATCC } \\
1022\end{array}$ \\
\hline SKW 402 & MW261810 & $100 \%$ & 0 & $99.46 \%$ & KU933446.1 & $\begin{array}{c}\text { Penicillium cremeogriseum } \\
\text { strain ATCC 18323 }\end{array}$ \\
\hline SKW 403 & MW261811 & $99 \%$ & 0 & $99.60 \%$ & NR_153214.1 & $\begin{array}{c}\text { Penicillium meleagrinum var. } \\
\text { viridiflavum CBS }\end{array}$ \\
\hline SKW 404 & MW261812 & $100 \%$ & 0 & $100 \%$ & N35.59 \\
\hline SKW 405 & MW261813 & $98 \%$ & 0 & $99.82 \%$ & KY937924.1 & $\begin{array}{c}\text { Aspergillus fumigatus ATCC } \\
1022\end{array}$ \\
\hline SKW 407 & MW261814 & $100 \%$ & 0 & $100 \%$ & NR_134419.1 & $\begin{array}{c}\text { Trichoderma yunnanense CBS } \\
\text { CCT 7615 } \\
121219\end{array}$ \\
\hline
\end{tabular}


Interestingly, to the best of our knowledge, this is the first reported isolation and identification of Penicillium panissanguineum (SKW 104), Penicillium cremeogriseum (SKW 402), Aspergillus bertholletius (SKW 405) and Trichoderma yunnanense (SKW 407) in Sri Lanka. This may indicate the relatively higher possibility of discovering novel microbial species from Sri Lankan caves, which are yet to be explored.

Cave wall isolate SKW 404 and cave ceiling isolate SKW 301 were shown to have the highest query coverage $(100 \%)$ and percentage identity $(100 \%)$ and both of these cultures were identified as Aspergillus fumigatus strains. A. fumigatus is well known as an opportunistic human pathogenic fungus associated with the respiratory tract which causes aspergillosis (Perfect et al., 2001). The fungi $A$. fumigatus has also been reported in cave sediments and air in previous publications (Griffiths, 1979; Nováková, 2009; Taylor et al., 2017).

\section{Primary screening of cave microbial isolates for their antimicrobial activity}

Among all the tested fungal isolates, only three out of eight isolates (SKW 301, SKW 404 and SKW 407) showed antimicrobial activities at least against one human pathogen for each. Accordingly, the fungal isolate from cave ceiling SKW 301 and the cave wall isolate SKW 404 expressed antimicrobial activities against Gram-positive $S$. aureus, while the fungal isolate from cave wall SKW 407 expressed antimicrobial activity against Gram-negative $P$. aeruginosa. None of the Cave wall/ceiling fungal isolates were able to show any antimicrobial activity against E. coli, C. albicans and C. parapsilosis. Lack of the original culture conditions and the exact nutrient requirements may have led to the suppression of any antimicrobial compound production in the used growth media which indicates the necessity of further investigations using different culture media and culture conditions.

The data shown in Table 4 represent the results of an individual primary screening step of all the cave wall/ceiling fungal isolates giving positive results with three replicates and the data are shown as Mean \pm SD. The diameters of ZOI were obtained to compare the antimicrobial activities against similar human pathogenic microorganisms and based on the relative antimicrobial activity, only A. fumigatus isolate SKW 404 was selected for further studies against S. aureus.

Table 4. Repeated primary screening results of the cave wall/ceiling fungal isolates showing antimicrobial activity assayed by agar culture plug method on MHA.

\begin{tabular}{|c|c|c|c|c|}
\hline \multirow{2}{*}{ Strain No } & \multicolumn{2}{|c|}{$\begin{array}{l}\text { Mean Diameter of } \mathrm{ZOI}^{*} \text { as given } \\
\text { by fungal isolates }(\mathrm{mm})(\mathrm{n}=3)\end{array}$} & \multicolumn{2}{|c|}{$\begin{array}{l}\text { Mean Diameter of } \mathrm{ZOI}^{*} \text { as given by Positive } \\
\text { control }(\mathrm{mm})(\mathrm{n}=3)\end{array}$} \\
\hline & S. aureus & P. aeruginosa & Chloramphenicol (30 $\mu \mathrm{g} /$ disk) & Gentamicin (10ug/disk) \\
\hline SKW 301 & $11.22 \pm 0.19$ & - & $40 \pm 0.00(\mathrm{~S})$ & $-(\mathrm{R})$ \\
\hline SKW 404 & $17.22 \pm 0.38$ & - & $40 \pm 0.00(\mathrm{~S})$ & - (R) \\
\hline SKW 407 & - & $9.67 \pm 0.57$ & - (R) & $19 \pm 0.00(\mathrm{~S})$ \\
\hline
\end{tabular}

*ZOI includes the diameter of the standard antibiotic disks (6 mm) or agar culture plugs $(6 \mathrm{~mm})$ from 10 day old fungal cultures grown on $\mathrm{PDA}$ at $25^{\circ} \mathrm{C}$, (S): susceptible and (R): resistant according to CLSI (2015).

Interestingly, A. fumigatus is known to produce secondary metabolites which can be harmful or medically important. Fumagillin was first discovered in the 1950 s which was introduced as an antimicrobial compound and is produced by A. fumigatus. Later, it was also introduced as an angiogenesis inhibitor for the treatments of cancer and as an agent to inhibit the growth of malaria parasites in vitro. Other than fumagillin, antimicrobial compounds such as asperffumoid, helvolic acid, deoxypodophyllotoxin and fumigaclavine have also been described in the literature as being produced by $A$. fumigatus. (Liu et al., 2004; Boudra \& Morgavi, 2005; Lamrani et al., 2008; Kusari et al, 2009; Compaoré et al., 2016).

Secondary screening of antimicrobial compounds

The obtained results from the $\mathrm{KB}$ disk diffusion assay using both SKW 404 mycelial (intracellular) and PDB culture broth (extracellular) EtOAc crude extracts shown to have similar antimicrobial activities against human pathogenic S. aureus (Table 5). However, the intracellular EtOAc crude extract had slightly higher antimicrobial activity $(22.83 \pm 0.29 \mathrm{~mm})$ than the crudes obtained from extracellular material (21.17 \pm $0.29 \mathrm{~mm})$.

Table 5. In vitro antimicrobial activity of the SKW 404 EtOAc crude extracts.

\begin{tabular}{|c|c|c|c|}
\hline \multirow{2}{*}{ Crude origin } & \multicolumn{2}{|c|}{$\begin{array}{c}\text { Mean Diameter of ZOI } \pm \text { SD }(\mathrm{mm})(\mathrm{n}=3) \\
\text { against S. aureus }\end{array}$} & \multirow{2}{*}{$\begin{array}{c}\text { Mean Diameter of ZOI } \pm \text { SD }(\mathrm{mm}) \\
(\mathrm{n}=3) \text { of Chloramphenicol }(30 \mathrm{\mu g} / \\
\text { disk) against S. aureus }\end{array}$} \\
\hline & $400 \mu \mathrm{g} / \mathrm{disc}$ & $40 \mu \mathrm{g} / \mathrm{disc}$ & \\
\hline Intracellular & $22.83 \pm 0.29^{*}$ & $11.33 \pm 0.29$ & $40 \pm 0.00(\mathrm{~S})$ \\
\hline Extracellular & $21.17 \pm 0.29$ & $10.33 \pm 0.29$ & $40 \pm 0.00(\mathrm{~S})$ \\
\hline
\end{tabular}

*ZOI includes the diameter of the paper disk (6 mm), (S): susceptible and (R): resistant according to CLSI (2015).

This slight difference in antimicrobial activity could be due to the degradation of extracellular biomolecules (Seidel, 2006). It can occur during both fermentation and extraction procedures and also has been shown that removal of solvent should be done immediately since several microbial metabolites are unstable in solution. Furthermore, avoidance of prolonged exposure to sunlight is 
vital to protect them from potential degradation (Seidel, 2006).

Based on the results obtained from applying different amounts of crude extracts, $400 \mu \mathrm{g}$ per disk was chosen for further tests since larger diameters result in a lower relative error in measuring the ZOI diameters.

\section{Thermostability test}

The thermal stability of bioactive metabolites is a crucial property in the use of many therapeutic applications and also for biotechnological applications (Tanhaeian et al., 2020). Furthermore, higher thermostability is an extra advantage for the extraction processes since it can reduce extraction time (due to higher vaporization rate in higher temperature without affecting the bioactive metabolites) and considering the cold storage facility limitations.

Both intracellular and extracellular EtOAc crude extracts of SKW 404 demonstrated higher thermal stability with no effect to its antimicrobial activity even after incubating the crude extracts at $75^{\circ} \mathrm{C}$ for 15 minutes (Table 6).

Highly thermostable (up to $70^{\circ} \mathrm{C}$ ) novel antifungal peptide from Aspergillus clavatus has recorded by Skouri-Gargouri \& Gargouri (2008). However, highly thermostable antibiotics can also contribute to emerging antibiotic resistance since many farm products are shown to contain a relatively high amount of antibiotic residues and these are hardly degraded by cooking steps (Tian et al., 2017).

\section{TLC: Bioautography}

TLC is a widely used method for isolating and analyzing small organic compounds (natural and synthetic) products from complex mixtures since it is inexpensive, rapid, and easy compared to other parallel methods. This method can also be easily combined with other methods for the biological evaluation of bioactive secondary metabolites (Gibbons, 2012). The agar-overlay method is a bioautography method known to result in well-defined ZOI while not being sensitive to contaminations. Active compounds separated on the TLC plates (stationary phase) are diffused to the media seeded with the target microorganism. This method has successfully used a number of target microorganisms, including bacterial and yeast pathogens (Marston, 2011; Balouiri et al., 2016).

Both extracellular and intracellular EtOAc extracts of SKW 404 had similar profiles. A minimum of four spots which are corresponding to the antimicrobial activity was observed from both intracellular and extracellular EtOAc crude extracts. Several fractions including, Fraction $4\left(\mathrm{~F} 4, R_{f}=0.82\right)$ and Fraction 1 $\left(\mathrm{F} 1, R_{f}=0.47\right)$ from intracellular crude extracts shown to have higher antimicrobial activity compared to Fraction $2\left(\mathrm{~F} 2, R_{f}=0.56\right)$ and Fraction $3\left(\mathrm{~F} 3, R_{f}=0.65\right)$.

Table 6. Thermostability of the antimicrobial compound/s in the SKW 404 EtOAc crude extracts against S. aureus.

\begin{tabular}{|c|c|c|}
\hline \multirow{2}{*}{ Temperature } & \multicolumn{2}{|c|}{$\begin{array}{c}\text { Mean Diameter of } \mathrm{ZOI} \pm \mathrm{SD}(\mathrm{mm})(\mathrm{n}=3) \\
\text { against } \mathrm{S} \text {. aureus }\end{array}$} \\
\hline & Intracellular crude extract & Extracellular crude extract \\
\hline Control $\left(25 \pm 2^{\circ} \mathrm{C}\right)$ & $13.16 \pm 0.29^{*}$ & $12.83 \pm 0.29$ \\
\hline $55 \pm 2^{\circ} \mathrm{C}$ & $13.16 \pm 0.29$ & $12.83 \pm 0.29$ \\
\hline $75 \pm 2^{\circ} \mathrm{C}$ & $13.16 \pm 0.29$ & $12.83 \pm 0.29$ \\
\hline
\end{tabular}

*ZOI includes the diameter of the paper disk $(6 \mathrm{~mm})$. The concentration of the applied disks was $400 \mu \mathrm{g} / \mathrm{disk}$.

Overall, the bioactive fractions of each crude extract of SKW 404 (intracellular and extracellular) had similar $R_{f}$ values and showed good reproducibility.

Since the $R_{f}$ is a unique value for each chemical compound under the same mobile phase conditions, the crude extracts with similar metabolic profiles can be pooled together in further investigations.

\section{CONCLUSION}

To the best of our knowledge, this is the first microbiological attempt in Sri Lanka to isolate, identify and bioprospect of cave-dwelling microorganisms. The current research findings suggested that the microorganisms inhabiting the Sthreepura Cave sediments could be acidophilic extremophiles that can be further studied in future research on geomicrobiology, astrobiology, and bioprospecting of extremozymes and bioactive metabolites (Gabriel \& Northup, 2013; Wurster et al., 2015; Johnson \& Schippers, 2017; Rathinam \& Sani, 2018; Merino et al., 2019). Although the exact nutrient and mineral availability of the Sthreepura Cave - Kuruwita sediment samples are yet to be evaluated, the available literature and the data obtained from this study may provide information required for future cave microbiological studies.

The molecular identification of the wall/ceiling fungal isolates revealed that four out of eight isolates, $P$. panissanguineu, $P$. cremeogriseum, A. bertholletius and T. yunnanens as the first records of isolation and identification in Sri Lanka. Thus, this may indicate the potential hidden microbial biodiversity in Sri Lankan caves, which are yet to be explored. However, detailed taxonomic studies must be performed to identify the cave fungal isolates accurately, which might be useful in future cave microbiological investigations.

Out of the all tested eight cave wall/ceiling dwelling fungal isolates, two strains of $A$. fumigatus (SKW 301 and SKW 404) and T. yunnanense (SKW 407) shown to have antimicrobial activities against human pathogenic bacteria $S$. aureus and $P$. aeruginosa, respectively.

The both mycelial (intracellular) and PDB culture broth (extracellular) EtOAc extracts obtained from 15 days old PDB of A. fumigatus (SKW 404 strain) had promising antimicrobial activities against $S$. aureus and a higher thermostability even at $75^{\circ} \mathrm{C}$. Four 
chemical fractions corresponding to the antimicrobial activities against $S$. aureus were identified in both intracellular and extracellular EtOAc crude extracts of A. fumigatus (SKW 404), using modified agar overlay bioautography method. The $R_{f}$ values were $0.47,0.56,0.65$, and 0.82 [mobile system; EtOAc: Hexane, $1 / 4(\mathrm{v} / \mathrm{v})]$. Based on the TLC results, the antimicrobial compounds can be identified as slightly nonpolar metabolites, although further investigations are required for the accurate identification of the chemical compounds.

Further in-depth investigations must be conducted for a better understanding of the cave microbial ecology and to obtain a higher number of isolates, since is important to discover more bacterial species, especially rare actinobacterial species with potential bioactive compounds. Hence, studies on other types of caves are also recommended as Sri Lanka known is known to harbour a diverse climatic and geological variations.

\section{ACKNOWLEDGEMENTS}

This research project was funded by the Department of Botany, University of Sri Jayewardenepura, Sri Lanka (USJ). The authors would like to thank Lanka institute of Cave Sciences (LICAS), Mr S. Dilshan and $\mathrm{Mr} \mathrm{H}$. Jayamaha for their invaluable support during the sample collection process and Miss S. Hussain, Mr B. Darmasena, Miss V. S. Kaluthanthri, Mr. T. Chamara, Mrs.H. S. Ferdinandez and Miss N. Pathmanathan for their aid during laboratory experiments. We thank Mr M. C. Prabhath and Miss I. A. Hristea for their constructive criticisms and suggestions. We also extend our special thanks to Prof. N. Saleem (Department of Botany, USJ) and Prof. M. Vithanage (Ecosphere Resilience Research Center, Faculty of Applied Sciences, USJ), Dr R. Dissanayake (Department of Pharmacy, USJ) for granting us the necessary laboratory facilities. Our sincere thanks go to Prof. Hazel Barton (Associate Editor, IJS) and two anonymous reviewers for their suggestions and comments to improve the content of this manuscript.

Authorship statement: EIPS conceived, designed, sampled, performed all the experiments, analyzed the data, and wrote the-manuscript. PJ, SS, and AD aided caving and sampling. DHM supervised the research project. DHM and PJ edited the manuscript.

\section{REFERENCES}

Amann, R.I., Ludwig, W., Schleifer, K.H., 1995. Phylogenetic identification and in situ detection of individual microbial cells without cultivation. Microbiology and Molecular Biology Reviews, 59(1), 143-169.

https://doi.org/10.1128/MMBR.59.1.143-169.1995

Arnold, A.E., Lutzoni, F., 2007. Diversity and host range of foliar fungal endophytes: are tropical leaves biodiversity hotspots? Ecology, 88(3), 541-549.

https://doi.org/10.1890/05-1459

Balouiri, M., Sadiki, M., Ibnsouda, S.K., 2016. Methods for in vitro evaluating antimicrobial activity: A review. Journal of Pharmaceutical Analysis, 6(2), 71-79.

https://doi.org/10.1016/j.jpha.2015.11.005
Barakat, K.M., Gohar, Y.M., 2012. Antimicrobial agents produced by marine Aspergillus terreus var. africanus against some virulent fish pathogens. Indian Journal of Microbiology, 52(3), 366-372.

https://doi.org/10.1007/s12088-012-0255-1

Belyagoubi, L., Belyagoubi-Benhammou, N., Jurado, V., Dupont, J., Lacoste, S., Djebbah, F., Ounadjela, F.Z., Benaissa, S., Habi, S., Abdelouahid, D.E., SaizJimenez, C., 2018. Antimicrobial activities of culturable microorganisms (actinomycetes and fungi) isolated from Chaabe Cave, Algeria. International Journal of Speleology, 47(2), 189-199.

https://doi.org/10.5038/1827-806X.47.2.2148

Bennett, J.W., 2015. What is an antibiotic. In: Sánchez, S., Demain, AL (Eds.), Antibiotics: current innovations and future trends. Caister Academic Press, Norfolk p. 1-18. https://doi.org/10.21775/9781908230546

Bérdy, J., 2015. Microorganisms producing antibiotics. In: Sánchez, S., Demain, AL (Eds.), Antibiotics: current innovations and future trends. Caister Academic Press, Norfolk, p. 49-64. https://doi.org/10.21775/9781908230546

Boudra, H., Morgavi, D.P., 2005. Mycotoxin risk evaluation in feeds contaminated by Aspergillus fumigatus. Animal Feed Science and Technology, 120(1-2), 113-123.

https://doi.org/10.1016/j.anifeedsci.2005.01.006

Cappuccino, J.G., Welsh T.C., 2017. Microbiology: A laboratory manual $\left(11^{\text {th }}\right.$ Ed.), Pearson Education, London, p. 251-253.

Cheeptham, N., 2013. Advances and challenges in studying cave microbial diversity. In: Cheeptham, N. (Ed.), Cave microbiomes: A novel resource for drug discovery. Springer, New York, p. 1-34.

https://doi.org/10.1007/978-1-4614-5206-5_1

Cheeptham, N., Sadoway, T., Rule, D., Watson, K., Moote, P., Soliman, L.C., Azad, N., Donkor, K., Horne, D., 2013. Cure from the cave: volcanic cave actinomycetes and their potential in drug discovery. International Journal of Speleology, 42(1), 35-47.

https://doi.org/10.5038/1827-806X.42.1.5

Cheeptham, N., Sáiz-Jiménez, C., 2015. New sources of antibiotics: Caves. In: Sánchez, S., Demain, AL (Eds.), Antibiotics: current innovations and future trends. Caister Academic Press, Norfolk, p. 213-227. https://doi.org/10.21775/9781908230546.12

Cho, Y.J., Park, J.P., Hwang, H.J., Kim, S.W., Choi, J.W., Yun, J.W., 2002. Production of red pigment by submerged culture of Paecilomycessinclairii. Letters in Applied Microbiology, 35(3), 195-202. https://doi.org/10.1046/j.1472-765X.2002.01168.x

Choi, Y.W., Hyde, K.D., Ho, W.H., 1999. Single spore isolation of fungi. Fungal Diversity, 29-38. https://doi.org/10.7872/crym.v34.iss4.2013.349

Clatworthy, A.E., Pierson, E., Hung, D.T., 2007. Targeting virulence: a new paradigm for antimicrobial therapy. Nature Chemical Biology, 3(9), 541-548. https://doi.org/10.1038/nchembio.2007.24

Clinical and Laboratory Standards Institute, 2015. Performance Standards for Antimicrobial Susceptibility Testing; Twenty-Fifth Informational Supplement. CLSI document M100-S25 (ISBN 1-56238-989-0 [Print]; ISBN 1-56238-990-4 [Electronic]). Clinical and Laboratory Standards Institute, 950 West Valley Road, Suite 2500, Wayne, Pennsylvania 19087 USA.

Compaoré, H., Sawadogo-Lingani, H., Guira, F., Waré, L.Y., Samandoulougou, S., Savadogo, A., Dianou, D., Traoré, S.A., 2016. Optimization of antimicrobial compound production by Aspergillus fumigatus 
isolated from maize in Ouagadougou, Burkina Faso. Current Research in Microbiology and Biotechnology, 4(4), 903-911.

Dandeniya, A.S., Champika, M., Elgiriya, P., Senanayake, S., 2009. Plan of the Sthreepura Cave, Kuruwita, Rathnapura. Scale 1:400, Lanka Institute of Cave Sciences (LICAS), Sri Lanka.

Davies, J., Davies, D., 2010. Origins and evolution of antibiotic resistance. Microbiology and Molecular Biology Reviews, 74(3), 417-433.

https://doi.org/10.1128/MMBR.00016-10

Fisher, S.C., Reilly, T.J., Jones, D.K., Benzel, W.M., Griffin, D.W., Loftin, K.A., Iwanowicz, L.R., Cohl, J.A., 2015, Standard operating procedure for collection of soil and sediment samples for the Sediment-bound Contaminant Resiliency and Response (SCoRR) strategy pilot study: U.S. Geological Survey Open-File Report 2015-1188b, p. 13-15. https://doi.org/10.3133/ofr20151188B

Gabriel, C.R., Northup, D.E., 2013. Microbial ecology: caves as an extreme habitat. In: Cheeptham, N. (Ed.), Cave microbiomes: a novel resource for drug discovery. Springer, New York, p. 85-108. https://doi.org/10.1007/978-1-4614-5206-5_5

Gibbons, S., 2012. An introduction to planar chromatography and its application to natural products isolation. In: Sarker, S.D., Nahar, L. (Eds.), Natural products isolation. Humana Press, Totowa, p. 117153. https://doi.org/10.1007/978-1-61779-624-1_6

Griffiths, P., 1979. Collection, culture and identification of soil microfungi from Florence Lake Cave near Victoria, B.C. Canadian Caver, 10, 35-38.

Hamedi, J., Kafshnouchi, M. and Ranjbaran, M., 2019. A study on actinobacterial diversity of Hampoeil cave and screening of their biological activities. Saudi Journal of Biological Sciences, 26(7), 1587-1595. https://doi.org/10.1016/j.sjbs.2018.10.010

Herold, K., Gollmick, F.A., Groth, I., Roth, M., Menzel, K.D., Möllmann, U., Gräfe, U., Hertweck, C., 2005. Cervimycin A-D: A polyketide glycoside complex from a cave bacterium can defeat vancomycin resistance. Chemistry-A European Journal, 11(19), 5523-5530. https://doi.org/10.1002/chem.200500320

Hudzicki, J., 2009. Kirby-Bauer disk diffusion susceptibility test protocol. Available at: https://www.asmscience.org/content/education/ protocol/protocol.3189.

Jayasingha, P., Osborne, LAR., Pogson, RE. 2018. Sthreepura Cave at Kiriwanagama. A network cave in weathered Proterozoic Gneiss and Quartzite. Acta Carsologica, 47(2-3), 109-122. https://doi.org/10.3986/ac.v47i2-3.4301

Jayasingha, P., Weliange, W.S., Dandeniya, A.S., Elgiriya, P., 2010. A classification for Sri Lankan caves. In: Proceedings of National Archaeological Symposium, p. 181-192.

Johnson, D.B., Schippers A., 2017. Editorial: Recent advances in acidophile microbiology: Fundamentals and applications. Frontiers in Microbiology, 8, 428. https://doi.org/10.3389/fmicb.2017.00428

Kusari, S., Lamshöft, M., Spiteller, M., 2009. Aspergillus fumigatus Fresenius, an endophytic fungus from Juniperus communis L. Horstmann as a novel source of the anticancer pro-drug deoxypodophyllotoxin. Journal of Applied Microbiology, 107(3), 1019-1030. https://doi.org/10.1111/j.1365-2672.2009.04285.x

Lamrani, K., Lakhtar, H., Alaoui, M.I., Ettalibi, M., Boiron, P., Augur, C., Perraud, I.G., Roussos, S., 2008. Production of fumagillin by Aspergillus fumigatus isolated from traditional trituration units, Maasra, in Morocco. Micología Aplicada International, 20(1), 35-41.

Liu, J.Y., Song, Y.C., Zhang, Z., Wang, L., Guo, Z.J., Zou, W.X., Tan, R.X., 2004. Aspergillus fumigatus CYO18, an endophytic fungus in Cynodondactylon as a versatile producer of new and bioactive metabolites. Journal of Biotechnology, 114(3), 279-287.

https://doi.org/10.1016/j.jbiotec.2004.07.008

Marston, A., 2011. Thin-layer chromatography with biological detection in phytochemistry. Journal of Chromatography A, 1218(19), 2676-2683. https://doi.org/10.1016/j.chroma.2010.12.068

Merino, N., Aronson, H.S., Bojanova, D.P., Feyhl-Buska, J., Wong, M.L., Zhang, S., Giovannelli, D., 2019. Living at the extremes: Extremophiles and the limits of life in a planetary context. Frontiers in Microbiology, 10, 780 p. https://doi.org/10.3389/fmicb.2019.00780

Montano, E.T., Henderson, L.O., 2013. Studies of antibiotic production by cave bacteria. In: Cheeptham, N. (Ed.), Cave microbiomes: A novel resource for drug discovery. Springer, New York, p. 109-130.

https://doi.org/10.1007/978-1-4614-5206-5 6

Moser, D.P., Boston, P.J., Martin, H.W., 2003. Caves and mines microbiological sampling. In: Bitton, G. (Ed.), Encyclopedia of environmental microbiology. John Wiley and Sons, New York, p. 821-835.

https://doi.org/10.1002/0471263397.env276

Niyomvong, N., Pathom-Aree, W., Thamchaipenet, A., Duangmal, K., 2012. Actinomycetes from tropical limestone caves. Chiang Mai ournal of Science, 39(3), 373-388.

Nováková, A. 2009. Microscopic fungi isolated from the Domica Cave system (Slovak Karst National Park, Slovakia). A review. International Journal of Speleology, 38, 71-82. https://doi.org/10.5038/1827-806X.38.1.8

Osborne, L.A.R., Weliange, W.S., Jayasingha, P., Dandeniya, A.S., Algiriya, A.P.P., Pogson, R.E., 2013. Caves and karst-like features in Proterozoic gneiss and Cambrian granite, southern and central Sri Lanka: an introduction. Acta Carsologica, 42(1), 25-48. https://doi.org/10.3986/ac.v42i1.630

Patridge, E., Gareiss, P., Kinch, M.S., Hoyer, D., 2016. An analysis of FDA-approved drugs: natural products and their derivatives. Drug Discovery Today, 21(2), 204207. https://doi.org/10.1016/j.drudis.2015.01.009

Paul, N.C., Lee, H.B., Lee, J.H., Shin, K.S., Ryu, T.H., Kwon, H.R., Kim, Y.K., Youn, Y.N., Yu, S.H., 2014. Endophytic fungi from LyciumchinenseMill and characterization of two new Korean records of Colletotrichum. International Journal of Molecular Sciences, 15(9), 15272-15286. https://doi.org/10.3390/ijms 150915272

Perfect, J., Cox, G.M., Lee, J.Y., Kauffman, C.A., De Repentigny, L., Chapman, S.W., Morrison, V.A., Pappas, P., Hiemenz, J.W., Stevens, D.A., 2001. The impact of culture isolation of Aspergillus species: a hospital-based survey of aspergillosis. Clinical Infectious Diseases, 33(11), 1824-1833.

https://doi.org/10.1086/323900

Rathinam, N.K., Sani, R.K., 2018. Bioprospecting of extremophiles for biotechnology applications. In: Sani, R.K., Rathinam, N.K. (Eds.), Extremophilic microbial processing of lignocellulosic feedstocks to biofuels, value-added products, and usable power. Springer, Cham, 1-23. https://doi.org/10.1007/978-3-319-74459-9 1

Reed, J.F., Cummings, R.W., 1945. Soil reaction-glass electrode and colorimetric methods for determining $\mathrm{pH}$ values of soils. Soil Science, 59(1), 97-105. 
Seidel, V., 2006. Initial and bulk extraction. In: Sarker, S.D., Nahar, L. (Eds.), Natural products isolation. Humana Press, Totowa, p. 27-46. https://doi.org/10.1007/978-1-61779-624-1_2

Shahack-Gross, R., Berna, F., Karkanas, P., Weiner, S., 2004. Bat guano and preservation of archaeological remains in cave sites. Journal of Archaeological Science, 31(9), 1259-1272. https://doi.org/10.1016/j.jas.2004.02.004

Skouri-Gargouri, H., Gargouri, A., 2008. First isolation of a novel thermostable antifungal peptide secreted by Aspergillus clavatus. Peptides, 29(11), 1871-1877. https://doi.org/10.1016/j.peptides.2008.07.005

Spizek, J., Havlicek, V., 2015. Tackling antibiotic resistance. In: Sánchez, S., Demain, A.L. (Eds.), Antibiotics: current innovations and future trends. Caister Academic Press, North Folk, p. 83-93. https://doi.org/10.21775/9781908230546.05

Sumanarathna, A.R., Wijayathunga, W.A.L.K., Silva, E.I.P., Hathalahawaththa, D.K., Fernando G.W.A.R., Sewwnadi, S.L., Silva, A.C., 2016. An assessement of geological formation of the rakwana-pannila mountain of Sri Lanka; Journal of Eco Astronomy 1(1), 32-42.

Tanhaeian, A., Mohammadi, E., Mansury, D., Zeinali, T., 2020. Assessment of a novel antimicrobial peptide against clinically isolated animal pathogens and prediction of its thermal-stability. Microbial Drug Resistance, 26(4), 412-419. https://doi.org/10.1089/mdr.2019.0062

Taylor, E.L., Ferreira, G.F., Freitas, G.J., Ferreira, R.L., de Assis Santos, D., de Resende-Stoianoff, M.A., 2017. Screening of antifungal susceptibility in cave-dwelling aspergilli and report of an amphotericin B-resistant Aspergillus flavus. International Journal of Speleology, 46(3), 369-378.

https://scholarcommons.usf.edu/ijs/vol46/iss3/5

Tian, L., Khalil, S., Bayen, S., 2017. Effect of thermal treatments on the degradation of antibiotic residues in food. Critical Reviews in Food Science and Nutrition, 57(17), 3760-3770. https://doi.org/10.1080/10408398.2016.1164119

Trisuwan, K., Rukachaisirikul, V., Sukpondma, Y., Preedanon, S., Phongpaichit, S., Sakayaroj, J., 2009. Pyrone derivatives from the marine-derived fungus Nigrospora sp. PSU-F18. Phytochemistry, 70(4), 554557. https://doi.org/10.1016/j.phytochem.2009.01.008

Vartoukian, S.R., Palmer, R.M., Wade, W.G., 2010. Strategies for culture of 'unculturable' bacteria. FEMS Microbiology Letters, 309(1), 1-7. https://doi.org/10.1111/j.1574-6968.2010.02000.x

Wang, M.H., Li, X.M., Li, C.S., Ji, N.Y., Wang, B.G., 2013. Secondary metabolites from Penicillium pinophilum SD-272, a marine sediment-derived fungus. Marine Drugs, 11(6), 2230-2238. https://doi.org/10.3390/md11062230

Weliange, W.S., Dandeniya A.S., Elgiriya, P., Dewage, D.D., Alahakoon, A.M.D., Hettiaarchchi, N., Jayasingha, P., 2010. Speleological exploration to Sthreepura Lena cave at Kuruwita, Sri Lanka. National Archaeological Symposium.

White, T.J., Bruns, T., Lee, S.J.W.T., Taylor, J., 1990. Amplification and direct sequencing of fungal ribosomal RNA genes for phylogenetics. PCR Protocols: A Guide to Methods and Applications, 18(1), 315-322. https://doi.org/10.1016/b978-0-12-372180-8.50042-1 Williams, S.T., Davies, F.L., Mayfield, C.I., Khan, M.R., 1970. Studies on the ecology of actinomycetes in soil II. The $\mathrm{pH}$ requirements of streptomycetes from two acid soils. Soil Biology and Biochemistry, 3(3), 187-195. https://doi.org/10.1016/0038-0717(71)90014-9

Wurster, C.M., Munksgaard, N., Zwart, C., Bird, M., 2015. The biogeochemistry of insectivorous cave guano: a case study from insular Southeast Asia. Biogeochemistry, 124(1-3), 163-175. https://doi.org/10.1007/s10533-015-0089-0

Yücel, S.E.M.R.A., Yamaç, M.U.S.T.A.F.A., 2010. Selection of Streptomyces isolates from Turkish karstic caves against antibiotic resistant microorganisms. Pakistan Journal of Pharmaceutical Sciences, 23(1), $1-6$. 